\title{
In-Service Education, Professional Development of Mathematics Teachers
}

\author{
Shuhua An and Andrea Peter-Koop
}

The aim of TSG 25 at ICME-12 was to discuss the experiences and approaches developed in different countries to support the professional development of teachers for practice, in practice and from practice. The study group 25 received 74 paper submissions from scholars, graduates, and practitioners in various countries and regions, and accepted 69 papers. A total of 63 papers were presented at 10 sessions at ICME 12 conference. Participants discussed research based practices and stateof-the-art approaches to the in-service education and professional development of teachers from a multi-national and globe perspectives. This report will address some key ideas in the following topics from TSG 25:

- Research studies and projects in professional development of primary and secondary school teachers

- Research studies and projects in in-service education and teacher education programs

- Classroom teaching research and lesson study in professional development of primary and secondary school teachers

- In-service education in STEM field in secondary school settings-Research studies and projects

- Mentor and coaching programs in professional development of primary and secondary school teachers

Organizers Co-chairs: Shuhua An (USA), Andrea Peter-Koop (Germany); Team Members: Barbara Clarke (Australia), Yimin Cao (China), Gooyeon Kim (Korea); Liaison IPC Member: Gabriele Kaiser (Germany).

S. An $(\square)$

California State University, Long Beach, Long Beach, USA

e-mail: san@csulb.edu

A. Peter-Koop

Institut für Didaktik der Mathematik, Universität Bielefeld, Bielefeld, Germany

e-mail: andrea.peter-koop@uni-bielefeld.de

(C) The Author(s) 2015

S.J. Cho (ed.), The Proceedings of the 12th International Congress

on Mathematical Education, DOI 10.1007/978-3-319-12688-3_50 


\section{Professional Development of Primary and Secondary School Teachers}

One of the challenges in teacher professional development is the nature of the research and the differing agendas of stakeholders. Much of the research takes the form of evaluation of teacher development projects and while they build on a growing body of research, the contexts in which they occur are complex. As a result it is difficult to synthesize the findings in ways that can inform future planning. How can our small pieces of research contribute to our understanding of the whole picture?

The role of teacher attitudes within the context of professional development is important but can be overemphasized at the expense of actions. A number of the papers helped focus on the role of practice in teacher development. The value of ensuring that participants have a voice was a common theme.

The important discussion focused on content of professional development and measurement of effects of professional development. A number of papers indicated the needs of paying attention to specific knowledge, such as error analysis, and measuring teachers' knowledge and teacher learning from error analysis and engaging learners in avoiding the errors.

Participants discussed the forms of professional development. Presentations shared different forms of lesson studies, such as Teacher Research Group in China, an important form of school based professional development.

\section{In-Service Education and Teacher Education Programs}

The presentations shared their effective approaches in in-service education and teacher education programs. However, the discussions indicated the challenges in in-service education and teacher education programs. The examples of the challenges: (1) How can we best prepare math teachers? (2) How to measure teachers' pedagogical content knowledge, (3) How to support new teachers and teacher retention issue, (4) Design different models of professional development that support teachers in new initiatives, (5) Relationship between professional development and classroom teaching, (6) Teaching work load and time to plan lesson in US, (7) Tools for reflection, and (8) Leadership roles.

\section{Classroom Teaching Research and Lesson Study in Professional Development and Teacher Education Programs}

Classroom teaching research and lesson studies have various forms in different countries. The following focused questions regarding classroom teaching research 
and lesson study in professional development of primary and secondary school teachers were asked during the discussions:

- What is effective classroom teaching?

- What math teacher educators should know about effective classroom teaching?

- How can we best prepare math teachers to teach math effectively?

- How do we enhance the effectiveness of professional learning communities for math teachers?

\section{In-Service Education in STEM Field in Secondary School Settings}

In-service education in secondary schools with a focus on integrating science and technology is an interesting topic of TSG 25 sessions. A range of contexts and countries were represented both in the papers and the discussions and there was considerable overlap in the issues of concern. The role of technology provides an added challenge as both software and hardware is constantly being updated. The comfort zone of teachers was a common issue and the acknowledgement that inservice education and professional development often requires teacher to move out of their comfort zone. This is particularly relevant in technology rich or cross discipline environments.

\section{Mentor and Coaching Programs in Professional Development of Primary and Secondary School Teachers}

There were a range of papers focusing on leading teacher change through a variety of models. Mentoring and coaching models are increasingly being used in many countries. One model that was particularly promising was "teacher researchers" in China. They are a form of master teacher with considerable expertise who supports teacher development. This systemic approach also provides for teacher progression within the profession that is not available in many countries.

\section{Whole Group Discussion}

The whole group discussion focused on key issues, major findings, insights, international trends in research and development in professional development and in-service education, and indicated open questions to be addressed in the future. 
Questions to be addressed in the future

- How do we support new teachers in the new initiatives?

- What are the different models of professional development? Especially, what are good models for new initiatives?

- What is the relationship between professional development and effective classroom teaching?

- What are the common strategies in professional development and classroom teaching in different countries? Diverse issue is needed to address also.

Discussion on future planning: Publications arising from TSG 25

- Publication of selected papers in an edited volume to be published by Springer Mathematics Teacher Education and Development series (Research based papers)

- Publication of selected papers in a special issue in Journal of Mathematics Education (USA) (Research based papers)

More opportunities:

- Routledge Education, Taylor \& Francis expressed their interest in publishing TSG 25 papers

- A journal editor from Singapore also expressed her interest in publishing TSG 25 papers in a special issue

\section{Joint project}

- Participants supported the idea to work together for a joint project that compares in-service education and professional development of mathematics teachers in different countries.

Open Access This chapter is distributed under the terms of the Creative Commons Attribution Noncommercial License, which permits any noncommercial use, distribution, and reproduction in any medium, provided the original author(s) and source are credited. 